\title{
EL FUNCIONALISMO RADICAL PENAL A PARTIR DE LA BIOÉTICA*
}

\section{Criminal radical functionalism from bioethics}

Henry Torres Vásquez ${ }^{* *}$, Misael Tirado Acero***, Sergio Trujillo Florián****

Recepción: 12 de julio de 2017. Aceptación: 08 julio de 2018

DOI: http://dx.doi.org/10.21017/Rev.Repub.2018.v25.a55

\section{RESUMEN}

La bioética admite reflexionar acerca de la pregunta: ¿Cómo se relaciona el funcionalismo penal y la bioética frente a los delitos, en especial los que atentan contra la seguridad pública? El objetivo es describir las escuelas sociológicas que han dotado al funcionalismo en materia penal y su relación con la bioética. Este artículo sugiere algunas líneas del pensamiento de la bioética principialista, la personalista y el sistémico sociológico mediante la investigación documental interpretativa y el proceso reflexivo se sustenta en la información obtenida y analizada en textos y artículos de revistas indexadas, con análisis

* Artículo de reflexión producto del proyecto de investigación Cultivadores de plantas de uso ilícito como víctimas. Enfoque biojurídico y penal del grupo de investigación «Derecho penal e implementación del sistema acusatorio» de la Universidad la Gran Colombia, 2017, y del Grupo de Investigación «Red de Estudios Sociojurídicos Comparados y Políticas Públicas -RESCYPP» de la Universidad Militar Nueva Granada.

** Abogado, doctor en Sistema Penal, con tesis doctoral con máxima calificación cum laude por unanimidad. Investigador asociado (1) reconocido por Colciencias. Correo electrónico: henry.torres@ugc.edu.co

*** Sociólogo de la Universidad Nacional de Colombia, con posgrados en Economía y Evaluación Social de Proyectos de la Universidad de los Andes. Doctorado en Sociología Jurídica e Instituciones Políticas de la Universidad Externado de Colombia. Posdoctorado en Derecho de la Universidad de Buenos Aires, Argentina. Par académico e institucional del Ministerio de Educación Nacional, par evaluador de Colciencias. Par CNA, Consultor de Naciones Unidas y de la Presidencia de la República. Docente-investigador. «Red de Estudios Sociojurídicos Comparados y Políticas Públicas -RESCYPP», Facultad de Derecho, Universidad Militar Nueva Granada. Correo electrónico: misaeltirado@gmail. com; misael.tirado@unimilitar.edu.co

**** Abogado, especialista en Derecho Penal, magíster en Derecho Penal y Doctorado en Curso en Bioética por la Universidad Militar Nueva Granada. Docente-investigador. «Red de Estudios Sociojurídicos Comparados y Políticas Públicas-RESCYPP», Facultad de Derecho, Universidad Militar Nueva Granada. Correo electrónico: sergiotrujillo abogado@hotmail.com; edwin.trujillo@unimilitar.edu.co 
crítico del discurso. Sobresale como conclusión principal que derecho penal actual necesita un análisis bioético para que no se vea socavada la dignidad humana.

Palabras clave: Derechos humanos, dignidad humana, funcionalismo, seguridad.

\begin{abstract}
Bioethics admits to reflect on the question: How does criminal functionalism and bioethics relate to crimes, especially those that threaten public safety? The objective is to describe the sociological schools that have endowed functionalism in criminal matters and its relationship with bioethics. This article suggests some lines of the thinking of principialist bioethics, the personalist and systemic sociological. Through interpretative documentary research and the reflexive process it is based on the information obtained and analyzed in texts and articles of indexed journals, with critical analysis of discourse. It stands out as the main conclusion that current criminal law needs a bioethical analysis so that human dignity is not undermined.
\end{abstract}

Key words: Functionalism, human dignity, human rights, security.

\title{
INTRODUCCIÓN
}

"Knowledge is power and whoever is able to develop or acquire and to deny the access of others to a kind of knowledge respected and sought by others; and whoever can control the channels by which it is communicated to those given access to it, will exercise a very special kind of structural power»

(Strange, 1994)

El clima político y social del siglo XXI ha dado lugar al surgimiento de claras manifestaciones xenofóbicas y extremistas en aras de salvaguardar la seguridad ciudadana. Esto ha conllevado a procesos de segregación y deshumanización de aquellos individuos que son percibidos como un riesgo para la sociedad. En el derecho penal se implementó un modelo funcionalista radical que vulnera derechos fundamentales y está en contravía del modelo finalista constituido bajo el principio del acto.

El derecho penal se ha modificado en sus principios y sus categorías como resultado de las interacciones sociales, presentes en el marco de la globalización; dicha reforma obedece al crecimiento de la xenofobia como fenómeno social arraigado en la manipulación mediática, sustentado a su vez en el incremento 
de las franjas de pobreza, los procesos migratorios y las guerras nacionales e internacionales, que han terminado por generar procesos de aversión marcados hacia ciertos grupos sociales o culturas. Estos fenómenos, han traído consigo una serie de modificaciones a la política criminal para mantener el statu quo y el orden social mediante las cuales se deshumaniza a los presuntos criminales, privándolos de sus derechos como resultado de procesos de exclusión y juicio social, los cuales inciden de forma más o menos amplia en la velocidad y eficiencia del proceso.

Las modificaciones sufridas por la política criminal -de corte funcionalista- han generado desconocimiento de derechos con la aplicación de sanciones irracionales. El sistema penal de índole disuasivo establece un llamado «peligrosísmo» y deja de lado el acto realizado por el individuo. Se ignoran los presupuestos teóricos de disuasión de la norma penal en la aplicación de la sanción, sustentada en la certeza de la sanción con penas cortas y no en el incremento de las penas como mecanismo de persuasión.

El funcionalismo como constructo sociológico -previo a su adaptación al derecho penal, desde los postulados de Parsons (1999) pregonaba por una visión matizada del utilitarismo de las acciones, pro del sostenimiento de una estabilidad y las formas preestablecidas de organización social. Esto transcendió al ámbito jurídico en la aplicación de las normas penales frente a los injustos jurídicos (Delitos o contravenciones) como forma de preservación del ordenamiento social. La función de la norma penal ${ }^{1}$, desde la teoría funcionalista, y como lo resalta Ferrari (2013), es generar «espacios» o «escenarios» de prevención, dentro de los cuales sobresalen uno general y otro especial; el primero encaminado a la persuasión social de cometer delitos y el segundo, frente al criminal en torno a una potencial reincidencia.

El garantismo penal de Ferrajoli, L. (2009) está en contraposición a este modelo, porque promueve para que el fin de toda sanción penal sea la eficacia y el respeto a los derechos de quienes se encuentran sujetos a una sanción penal, y los castigos son limitados por los principios elementales frente al ius puniendi del Estado. De esta manera, el modelo garantista penal funciona como límite a las arbitrariedades de un sistema penal autoritario e injusto, que busca socavar el modelo de Estado Social y Democrático de Derecho, y desconoce los fines fundamentales intrínsecos a las personas en los procesos de juzgamiento como son la justicia, la equidad y la seguridad jurídica.

1 Wright (1959) menciona que la función de la pena como mecanismo de disuasión ha sido ampliamente rebatida y en ocasiones por otras teorías; estipula que el incremento o modificación en las penas, más que disuadir a los individuos de incurrir en conductas criminales, genera un recrudecimiento de los actos criminales cometidos por estos. 
Potter (1971) utilizó el término bioética en un artículo denominado «bioethics the science of survival»; su propuesta fue crear una disciplina que permitiera unir la realidad y los valores, la ciencia y las humanidades, porque la distancia de las ciencias de la naturaleza y las humanas se hacía cada vez más lejana, denominando el fenómeno como la «crisis de hoy». El objetivo inicial de la bioética es trabajar a favor de la supervivencia del hombre y el medio ambiente del que depende; para el autor norteamericano la bioética debe ser la brújula que guíe las políticas públicas para alcanzar el bien social.

Gracia (1991) la entiende como la rama de la ética dedicada al estudio de los principios o máximas morales de comportamiento del ser humano en relación con la vida humana y no humana. Es susceptible de ser aplicada a la disciplina jurídica denominándose como «biojurídica»; y las leyes normativas, las sociales, las morales y las bioéticas deben regular las conductas de los habitantes, mediante la creación de deberes y derechos, que al ser aplicadas al ámbito del derecho penal deben garantizar el respeto unos mínimos fundamentales en respeto de unos principios y unos valores propios de la persona. La bioética no es reduccionista abarca todas las disciplinas y las ciencias del saber.

La bioética debe cuestionar y mediar en el desarrollo y aplicación del ámbito legislativo y jurisprudencial de afectación a la dignidad del individuo reducido a «enemigo» como resultado de la no adecuación de su comportamiento al rol social que le ha sido asignado o por contravenir el statu quo o las formas de control y organización social. Es necesario preguntar ¿De qué forma se puede relacionar la aplicación de los valores bioéticos al derecho penal de corte funcionalista para garantizar el respeto de las garantías mínimas fundamentales del individuo?

El artículo describe en primer lugar de manera sucinta las bases del funcionalismo penal, así como su posición respecto de la naturaleza humana; para proseguir a analizar los valores filosóficos que regentan la bioética desde una óptica principialista y personalista para que estos puedan ser incluidos y tenidos en cuenta por el funcionalismo penal en los procesos de aplicación del derecho penal a la sociedad.

\section{EL FUNCIONALISMO RADICAL Y SUS BASES}

Montero (2008) considera el funcionalismo como una corriente de pensamiento social que pregona por una visión matizada del utilitarismo de las acciones en pro del sostenimiento del estado de las cosas y las formas preestablecidas de organización social. Este saber se puede dividir en absoluto, relativo y estructural. 
El funcionalismo absoluto tiene su origen en los trabajos del llamado héroe etnográfico de la antropología, Malinowski (1981), quien consideró que en cada objeto, costumbre, idea o creencia se encuentra el cumplimiento intrínseco de una función indispensable para el sostenimiento de la sociedad, en tanto su existencia es condición sine qua non para el funcionamiento del andamiaje social.

El funcionalismo relativizado nace de la crítica de Merton (2002) hacia el absolutismo y cuestiona los postulados de la unidad funcional de la sociedad; es decir, no todo está integrado. Merton explica que no todas las estructuras sociales cumplen con la función aparente que dio lugar a su concepción, es decir que existe una disfuncionalidad que debe ser descubierta para evitar su transformación en un obstáculo frente al desarrollo y mantenimiento de los modelos sociales predominantes-.

El funcionalismo estructural encuentra sustento en los postulados de Parsons (1999), quien parte de una concepción de la «estructura social» para estipular que cada sociedad contiene elementos diferenciales que pueden unirse a pesar de sus diferencias; es decir, existe una correlación entre todas las partes del sistema. La obra de Parsons busca predecir y controlar; el énfasis de su teoría se enfoca en la acción social, y analiza al individuo en interacción con otros en el marco de un escenario determinado. Para esta teoría, el titular de la acción social es la persona que se comporta de acuerdo a un determinado rol, sin que ello limite la adopción de múltiples roles de acuerdo al escenario subyacente a la acción social realizada.

En materia de derecho penal, es necesario referirse a una vertiente del funcionalismo estructural, denominada sistémica, la cual se fundamenta en la teoría sociológica de Niklas Luhman (1983); esta teoría resalta el paso de los sistemas abiertos a los sistemas cerrados, lo cual implica una autoproducción del sistema, es decir, su autopoiesis. Se puede decir que esta teoría considera que «El derecho es un instrumento de estabilización social, que sirve para orientar las acciones de los asociados e institucionalizar las expectativas» (Velásquez, V. 2005, p. 199) y constituye la unidad productora de los sistemas la comunicación y sus múltiples formas.

Feijoo (2005) describe el modelo sistémico y afirma que las sociedades se encuentran compuestas por comunicaciones y no por individuos, de modo que las formas comunicativas siguen sus propias reglas que las llevan a asimilarse a los sistemas biológicos; por tanto, la función de los seres humanos es ser partícipes y ejecutores del sistema mediante actos comunicativos que nutren el constructo social, manifestándose la comunicación como la única operación específica de los sistemas sociales. 
Este tipo de funcionalismo guarda un mayor nivel de relación con el objeto de análisis de este artículo; es la obra de Luhmann aquella que ejerce mayor influencia en la construcción de la teoría de Jakobs (2005). Para el autor alemán, el sistema penal debe erigirse en torno a la sociedad, la norma y la persona; siendo la primera un sistema integrado por medio de la comunicación y la interacción entre individuos. La norma es una expectativa; no solo se espera algo del otro, sino que se valora la propia conducta con relación a un tercero y sus expectativas; en este sentido las normas jurídicas, desde la óptica del funcionalismo, son una expectativa de comportamiento de acuerdo a un rol social establecido que constituye a la persona ${ }^{2}$.

García (2008) considera el funcionalismo radical un poco más que una construcción social, diferente al individuo, y lo entiende como un concepto autorreferente, autopoiético y funcional, como lo es también un sistema psicofísico integrante y constitutivo de la sociedad, que comunica relevantemente. Esto se explica jurídicamente a través del funcionalismo sistémico porque los sistemas jurídicos, como subsistemas comunicativos, tienen una naturaleza autorreferencial -o autorreferente- que procesa la información que recibe del exterior autónomamente creando conceptos, sentidos, fines y objetivos, entre otros.

En esta teoría se hace imprescindible desligar la ética y la moral política del sistema jurídico por no constituir más que interferencia en los procesos de construcción de la comunicación jurídica. Afirma lo siguiente:

El derecho no es política ni economía, ni religión, ni educación. No produce obras de arte, ni cura enfermedades, ni distribuye noticias. Sin embargo, no podía existir si todas estas cosas no se dieran. Así, como todo sistema autopoiético, el derecho sigue dependiendo en gran medida de su entorno (Luhmann, N., 1983, p. 104).

Para esta teoría, la función del derecho en el interior del sistema y los subsistemas es la de reducir el caos en la comunicación entre los seres humanos al generar unos mínimos de comportamiento que permitan espacios de convivencia pacífica combinada con la seguridad en que los derechos se encuentran protegidos. Su especialidad son los delitos contra la seguridad pública y se fundamenta en la expectativa racional de cumplimiento de la norma por los otros miembros de la sociedad. En esta dinámica «la seguridad pública se dice que es mayor y mejor, cuando menor sea el grado de libertad, y consiguien-

2 Para Jakobs (2005) la finalidad del derecho penal es el mantenimiento de la vigencia normativa y la protección de los bienes jurídicos tutelados mediante los tipos penales, enmarcándose el desarrollo normativo en una óptica de derecho penal de enemigo. 
temente, es cuando entra en crisis la seguridad jurídica en términos de respeto a las garantías de los derechos de libertad, ya que se considera que la libertad es contraria a la seguridad del Estado.» (Torres, H., 2009, p. 142).

\title{
II. LA NATURALEZA DEL SER HUMANO PARA EL FUNCIONALISMO
}

\author{
"El niño que se haya visto severamente privado de contacto \\ social, como miembro de un grupo de juego, se hallará siempre en \\ situación de grave inferioridad en sus interacciones de adulto»
}

(Morris D. \& Aleu, JF. 1993)

Para Jakobs (2005) persona es aquel individuo que no debe ser lesionado y no tiene la potestad de lesionar a otro. Para el funcionalismo sistémico el concepto de persona está ligado al cumplimiento de la norma, como resultado de la función y rol que este cumple en el ámbito de lo social. Lo ontológico trasciende a lo deontológico en función de lo deontológico y la relación de la persona, este con los espacios de libertad, así como sus esferas de competencia. Solo puede ser tenido en cuenta como persona, quien cumple un papel útil socialmente, adecuándose al consenso, a la seguridad pública y al entorno, y si no lo hace pierde su estatus humano.

Se genera un proceso de diferenciación de los individuos en ciudadanos -personas- y enemigos -categoría que implica la pérdida de dignidad, derechos y el mismo estatus de humanidad-, situación que obedece a la necesidad sistémica de inmunidad por medio de preceptos sociales que deben dominar o prevalecer en la conducta de los asociados con la finalidad de mantener el orden establecido. El funcionalismo genera un criterio de división de los individuos, en el cual solo merece un trato digno quien es capaz de asumir su rol social. Nace el concepto «derecho penal de enemigo» como resultado de esta distinción.

El funcionalismo considera que se debe sancionar a un individuo (enemigo) por el mero peligro de realizar una conducta que lleve a la lesión del bien tutelado en incumplimiento de su rol social y secundariamente por la comisión de una conducta que de forma efectiva lesione un bien jurídico tutelado. Para la doctrina funcionalista:

Persona es quien se le adscribe el rol de un ciudadano respetuoso con el Derecho, y por ello, es persona real aquel cuyo comportamiento resulta adecuado a las normas. Para ello, se requieren dos condiciones: 1 . El comportamiento debe estar regido por las normas, porque ningún animal 
(entendido como parte del medio ambiente) puede ser una persona, y debe resultar adecuado a la norma (Polaino, M., 2004, pp. 227 y ss.).

Un habitante puede ser catalogado como persona cuando actúa y trata a los demás como tal; puesto que al contrariar las normas jurídicas que regulan el proceso de comunicación pierde su dignidad y todo merecimiento de respeto a sus derechos por parte de otros individuos. El concepto de utilidad social, implícito en esta diferenciación, debe ser comprendido desde un marco económico. Es persona, únicamente, quien siendo parte del sistema es útil a través de su productividad para el funcionamiento del mismo; siendo por lo tanto necesario apartar del sistema a aquellos cuya actividad no constituye un aporte al mismo.

Surge la necesidad de sancionar al individuo por no adaptarse a su rol social, más que por los actos cometidos; es decir, se propicia la aparición de un derecho penal de autor y no de acto, se retrocede al causalismo y se vulneran los derechos fundamentales de «enemigos naturales» a través de interceptaciones telefónicas, vigilancia continua, allanamientos de morada, entre otros, por ser medidas «necesarias» para mantener la seguridad pública por la amenaza que estos representan.

\section{LA NATURALEZA DEL SER HUMANO. PRINCIPIOS Y VALORES BIOÉTICOS}

\section{Dignidad humana}

El funcionalismo considera que la dignidad es únicamente atribuible a quienes por causa de su comportamiento y amistad con el Estado y su seguridad la han ganado. La bioética, sea principialista o personalista, cree que la dignidad es un fundamento que busca valorar al ser humano como individuo autónomo, individual y social, quien detenta una serie de particularidades y características propias del hecho de nacer. El ser humano merece derechos con independencia de su rol o forma de actuar en el interior del marco social, y la dignidad del individuo es un elemento sine qua non para su existencia.

Escobar-Picasso (2010) considera que el eje de todo debate de la bioética personalista es la persona y su cualidad de ser digna por encima de los derechos y los intereses de los demás. La dignidad como elemento fundamental del derecho constitucional y la bioética tiene su origen histórico en las largas luchas reivindicatorias por los derechos de los hombres, las cuales encontraron su punto cúlmine en la Declaración Universal de los Derechos Humanos de 1948, en donde se estipuló que todos los seres humanos son iguales y libres 
en sus derechos y en su dignidad, siendo esta última el pilar esencial para el disfrute de los derechos.

Esa situación es admitida en la Constitución Política por medio del artículo 1. ${ }^{\circ}$, el cual establece que Colombia es un Estado fundado en el respeto por este principio-valor ${ }^{3}$. Esta se desarrolla en materia penal, mediante el articulado de la Ley 599 de 2000, donde se establece en el artículo 1. ${ }^{\circ}$ que «El derecho penal tendrá como fundamento el respeto a la dignidad humana». Esto presupone que todo el articulado penal conformado por preceptos normativos y sanciones está constituido bajo la premisa de la dignidad.

Velásquez (2010) afirma que la dignidad constituye el límite material a la potestad que tiene el Estado para imponer sanciones mediante el derecho penal. Este apotegma viene a ser el más importante principio dentro de un Estado social y democrático de derecho, considera que funciona como el propulsor de la racionalización del derecho penal y la evolución de este. La dignidad posibilita que el ser humano no sea instrumentalizado desde el punto de vista punitivo, ni que sea objeto de sanciones criminales a fin de obtener el mantenimiento del sistema y su seguridad, aun cuando no haya cometido vulneración alguna a bienes jurídicos tutelados. Esta situación es nefasta, y se materializa en los modelos penales contemporáneos y de manera especial en el funcionalismo radical.

Los lineamientos funcionalistas radicales implementados en el ordenamiento jurídico positivo colombiano obedecen a parámetros de peligrosismo, bajo los cuales desaparece toda garantía de los derechos del acusado. A partir la óptica funcionalista, el núcleo de la imputación no gira en torno a la pregunta de si el hecho era evitable o cognoscible, sino de si el sujeto era competente para desplegar los deberes de seguridad en el tráfico o de protección frente a determinados derechos, para luego contestar si el hecho punible era evitable y cognoscible, a fin de mantener un statu quo.

El ejemplo es el que se presenta en el delito de concierto para delinquir que se describe en el artículo 340 del Código Penal, en especial el segundo y el tercer inciso (modificado por la Ley 1908 de 2018): se investiga y se juzga al individuo como resultado de concertarse con otro para la ejecución de un crimen, sin que se hubiese desplegado conducta alguna tendiente a la realización del mismo. Este artículo, que fue modificado en el año 2006 en procura de una «Política

3 La Constitución Política de Colombia hace igualmente referencia a la dignidad humana en materia laboral cuando en el último inciso del artículo 53 reza: «La ley, los contratos, los acuerdos y convenios de trabajo, no pueden menoscabar la libertad, la dignidad humana ni los derechos de los trabajadores». 
pública de seguridad democrática» y en el año 2018 se reformó para fortalecer la investigación y judicialización de organizaciones criminales, constituye una seria violación a las garantías derivadas de un derecho penal garantista, porque la acción penal se debe comenzar por el inicio de la ejecución de la conducta de los delitos que el artículo contempla y no por el pensamiento de quienes se llegan a concertar.

La Ley 1908 de 2018 es un claro ejemplo del afán del legislador por reformar los delitos contra la seguridad pública e implementar criterios funcionalistas radicales. Por ejemplo, en el artículo 340 que se analiza, las penas se incrementaron en cada inciso; las conductas se extendieron a los delitos contra la administración pública y el patrimonio del Estado, el contrabando en todas sus formas y el fraude aduanero; así como se incorpora en el Código Penal el artículo 340A sobre la asesoría a grupos delictivos, aunque excluye a los abogados. Estos deben acreditar el origen lícito de sus honorarios, es decir, la Ley presume que el pago de los recursos proviene de la ilicitud; por lo tanto, la defensa técnica será cuestionada con el fin de evitar una posterior acción de Extinción de Dominio, lo cual viola los principios de presunción de inocencia y de buena fe contractual.

El valor de un ser humano debe estar dado por su condición de tal y no por su servicio al entorno. Así se estipula en el artículo primero constitucional y los postulados bioéticos. Sin embargo, se menciona que para algunas corrientes bioéticas, la dignidad es susceptible de ser perdida o ganada; en este sentido debe mencionarse que existen al menos tres conceptos de dignidad desde la perspectiva bioética norteamericana que admiten esta posición.

Juárez (2004), a partir de la óptica de la bioética clínica, considera que la dignidad se debe al mérito obtenido en la sociedad -lineamiento claramente concordante con el funcionalismo-, y que también se debe medir conforme a la estatura moral de la persona dentro del conglomerado; y por la identidad del ser humano de acuerdo a su entorno y sus raíces, siendo esta última alterable por las relaciones con los demás o incluso las enfermedades. Conforme a lo anterior, es posible afirmar que la dignidad puede crecer, disminuir, o ser afectada por la condición del ser; esto contraría al valor constitucional según el cual los seres humanos nacen libres y con igual dignidad.

El principio de dignidad está constituido por dos proposiciones que vienen a ser las pautas que marcan el punto de partida para entender el límite de aplicación del mismo en materia de derechos. La primera está encaminada a proteger la autonomía ética de la persona humana porque el Estado no puede ejercer poder y dominio sobre el individuo menospreciando sus derechos, sino que es función del Estado dignificarlo. Kant (1983) manifestó que el ser humano, sin 
importar si se encuentra libre, condenado o en cualquier otra situación, no debe ser tratado como un medio, como una cosa, sino como un fin en sí mismo; de esta forma, afirma:

El hombre, y en general todo ser racional, existe como un fin en sí mismo, no solo como un medio para usos cualesquiera de esta o aquella voluntad; debe en todas sus acciones, no solo las dirigidas a sí mismo, sino las dirigidas a los demás seres racionales, ser considerado al mismo tiempo como un fin (...) obra de tal modo que uses la humanidad, tanto en tu persona como en la persona de cualquier otro, siempre como un fin al mismo tiempo, y nunca solamente como un medio (Kant, I. 1983, pp. 82 y 83).

La segunda proposición se refiere a la integridad de la persona, es decir, respetar su ser y no permitir que esta sea dañada en su vida, cuerpo y salud como ser social; de tal forma que los medios utilizados por el derecho penal no deben atentar contra la dignidad del ser humano, quien viene a ser convertido en un utensilio de dominio e inequidad ${ }^{4}$. En efecto, el valor fundamental del ser humano viene a frenar al Estado con su poder coactivo y punitivo, sin que pueda por lo tanto rebajarse la dignidad a justificar las conductas punibles que desea evitar en modelo de Estado social de derecho.

\section{Derecho penal y bioética}

Casado (1998) considera que la bioética tiende al reconocimiento de la pluralidad de opciones morales presentes en una sociedad, para establecer unos mínimos acuerdos. La bioética una rama de la ética, dedicada al estudio de los principios que rigen la conducta correcta del ser humano en un marco de interacción social, a esto se le denomina biojurídica. Para Goldschmidt (1958), la ética es parte fundamental de la norma jurídica, en sentido axiológico en concordancia con la teoría tridimensional del derecho por cuanto el derecho en su sentido «dikeológico» debe estar impregnado por valores como el orden, la seguridad y la igualdad, pero también debe estar constituida en pro de la vida y la dignidad del ser humano.

El «deber ser» de la moral es filtrar todas las esferas de la biojurídica, sea en la legalización, despenalización o prohibición de diferentes acciones u omisiones, a fin de evitar conceptos errados en los que se niega la relación del derecho con la moral, «La Biojurídica tiene por objeto el fundamento y pertinencia

4 En Colombia existe la prohibición de penas y medidas de seguridad donde se impongan tratos crueles, inhumanos y degradantes, así como la desaparición forzada, la confiscación de bienes, la pena de muerte, la cadena perpetua, entre otros. 
de las normas jurídicas positivas, para adecuarlas a los valores de la Bioética, estudia el contenido moral y ético de las leyes» (Samperio, C. y Barrachina, M., 2007, p. 53).

La bioética y su conceptualización parte de una serie de principios entre los cuales se resalta el respeto por los derechos humanos y la dignidad individual: la no maleficencia, beneficencia, justicia y autonomía; todos los cuales han demostrado ser de gran utilidad en la protección y materialización de los derechos humanos, a tal punto que la Unesco expidió en el año 2005 la Declaración Universal sobre Bioética y Derechos Humanos, cuyos objetivos están estipulados en el artículo 2, siendo importante resaltar el literal a, el cual establece como postulado: "proporcionar un marco universal de principios y procedimientos que sirvan de guía a los Estados en la formulación de legislaciones, políticas u otros instrumentos en el ámbito de la bioética».

La importancia de tomar a la bioética como referencia para la toma de decisiones legislativas y jurisprudenciales es indispensable; se deben tener en cuenta sus principios y valores, para que el marco normativo no llegue a afectar negativamente la autonomía del ser humano y el ideal de justicia.

\section{El Funcionalismo y los Principios de la Bioética}

La crítica al funcionalismo radical como escuela de gran influencia en el sistema jurídico del siglo XXI hace necesario sugerir la aplicación de los principios que rigen la bioética. Pues estos son el punto de partida de las normas de conducta, nacen producto de la escala de valores que rige un conglomerado social; independientemente de su nivel de aprendizaje, evolución o logro, son el fundamento de cualquier reglamentación, positivización o tipificación que pueda considerarse en la actualidad. El papel del principio no solo se queda en este propósito sino que viene a surtir el contenido de los derechos como se conocen hoy día.

El consenso existente en torno a la bioética es que los principios se soportan en el contenido de la dignidad, siendo este resultado de la aplicación de los mismos como mecanismo de protección a los individuos, en todas sus dimensiones y complejidades. En este consenso bioético, el derecho, desde una perspectiva tradicional, suele caer en el error de omitir los matices motivacionales de la conducta humana, cerrándose únicamente a la interpretación y aplicación de la norma en estricto sentido, desnaturalizándose, incluso a sí misma, en aras de cumplir su función de protección de la colectividad; mas en estas circunstancias, la bioética y -específicamente- la biojurídica dan un aire nuevo que trasciende lo meramente jurídico y le da un enfoque transdisciplinar, por medio del cual se tienen en cuenta los elementos sociales, culturales y científicos. 
De esta manera, el derecho se conforma como un sistema de normas que regulan los comportamientos relevantes en una sociedad. El derecho está dotado de mecanismos exigibles para propender por la armónica convivencia de quienes la componen, cuya actividad se mueve dentro de un marco de mínimos y máximos sujetos a la interpretación de quien opera el sistema jurídico. Tiene el riesgo de que la influencia de sus propios criterios y visiones del mundo y de las cosas haga tan flexible su particular aplicación de la ley, que finalmente la trasgreda; o que sea tan dura y rígida su aplicación, que termine desconociendo los derechos individuales en aras de proteger el valor de la legitimidad del sistema de seguridad, en las mismas líneas preestablecidas por el funcionalismo en materia penal.

Han sido múltiples las opiniones en torno a la prevalencia de unos principios sobre otros; por ejemplo, Amor, J. (2005) considera que los cuatro principios revisten una trascendental entidad, empero, al momento de sopesar uno sobre otro, desde el punto de vista bioético, dos (2) de ellos priman en forma absoluta y no pueden ser transgredidos de forma alguna en la toma de decisiones; estos son Justicia y No Maleficencia. Esta imposibilidad de transgresión implica que son de permanente aplicación y prevalecen como criterios de interpretación ante un eventual conflicto. Contrario a lo anterior, la Corte Constitucional Colombiana se ha referido al tema en asunto exclusivamente médico y la relación con el paciente:

Para resolver las colisiones entre estos principios de la bioética y entre los diferentes principios y derechos fundamentales que los soportan, la jurisprudencia constitucional ha sido enfática en indicar que, aunque la 'solución depende, en general, de la ponderación del peso específico que esos principios adquieren dadas las particularidades del caso concreto, (...) en una sociedad fundada en el pluralismo y la dignidad humana, el principio de permiso o de autonomía tiene una prevalencia prima facie sobre los otros principios concurrentes', por lo que, se reitera, todo tratamiento o procedimiento médico debe contar con el consentimiento idóneo del paciente (Corte Constitucional, 2010).

\section{No Maleficencia, sociabilidad y subsidiariedad}

El principio de No Maleficencia ha sido relacionado históricamente con el ejercicio médico y bajo una óptica de la bioética principialista de Beauchamp y Childress J. (1979), bajo las premisas de no causar daño y no matar. Este principio se aplica a todas las ciencias sociales y humanas, para establecer la prohibición de causar intencionalmente un daño o perjuicio -físico o mental-, o lesionar los intereses de otro de forma desproporcionada y sin justificación alguna para que el actuar de todos sea a partir de una perspectiva netamente kantiana, es decir con respecto a la dignidad humana. 
El estado de «Maleficencia funcionalista» se observa en aquellas conductas en las cuales, aunque no hay propósito de dañar, sí hay representación de la posibilidad de causar un perjuicio y, a pesar de esto, no se le da importancia al factor negligente y se aplica el denominado dolo eventual a una conducta netamente culposa. La corriente funcionalista en el contexto peligrosista afecta directamente el ejercicio de los derechos al autor de una conducta culposa, poniendo en él una intencionalidad que nunca se podría probar, máxime en los delitos contra la seguridad pública, porque el castigo viene a presentarse desde los actos de preparación o con los llamados tipos de peligro sin haberse lesionado derecho alguno. La norma hace que el individuo sea utilizado y desnaturalizado en un sentido utilitario-preventivo en pro del estado de cosas social.

Los principios de sociabilidad y subsidiariedad parten de una bioética personalista descrita por Burgos Velasco (2013), y parten del supuesto de que el ser humano es social y debe estar involucrado con la vida y la salud de los demás, y promover la ayuda para el bien común para respetar los derechos de los demás. También se debe respetar la capacidad de decisión y actuación frente a las instituciones y las organizaciones. Por lo tanto, el funcionalismo radical no permite que el ser humano se desarrolle como un ser social en pro del bienestar de los otros, sino que este simplemente debe cumplir su rol para mantener una estabilidad. El funcionalismo no permite la interacción y el desarrollo de los valores.

\section{Beneficencia}

El principio de beneficencia es un actuar que genere un provecho para otro, con la exigencia moral de hacer algo bueno para promover el mejoramiento de alguien más que, en un sentido ideal, podría llevar al propio, libre y desinteresado sacrificio; siendo, en definitiva, un acto de la voluntad y de la autonomía que se manifiesta ya no mediante la omisión, sino mediante la acción. Para Escobar y Aristizábal (2011) es posible derivar una serie de reglas morales consistentes en actuar de forma tal que se protejan y defiendan los derechos de los otros, se prevenga el daño causado por otros y se retiren las condiciones que puedan causar daños a otros.

Para la bioética el beneficiado sería el ser humano; para el funcionalismo radical el beneficiado sería la seguridad pública. Es manifiesto que no se trataría de un beneficio para el autor de la conducta peligrosa porque la limitación de sus propios derechos contraría los ejes de la doctrina peligrosista. El beneficio indirecto será la permanencia del sistema jurídico y la armonía social. Una sola decisión desencadena dos procesos de análisis bioético: primero, el de la afectación de los derechos del autor; y por el otro, la protección del conglomerado social, quien es destinatario de tal beneficio. 
El principio de beneficencia conlleva la necesidad de ponderar los beneficios y los riesgos; se beneficia la comunidad, pero se vulneran los derechos de la persona. El funcionalismo adopta como bien supremo la preservación del ordenamiento jurídico y la armonía social, califica los derechos del autor de un delito de peligro como derechos de segunda clase. El riesgo que se asume es de caer en un exceso paternalista justificado en la evitación del daño que el legislador imagina; empero, se vulnera en el proceso la integridad del sistema, porque no beneficia los derechos de los individuos.

Los delitos afectan la seguridad de la colectividad. Para Neuman (1983) se presenta el fenómeno de victimización primaria; sin embargo, la victimización secundaria (la acogida por el autor) se presenta cuando las tesis fundamentalistas de un Estado despótico lo alejan de una posible restauración y rehabilitación por parte de sus políticas de seguridad y alimentan la animosidad de las personas.

\section{Autonomía}

Para Ferro, Molina y Rodríguez (2009) el principio de autonomía -o respeto a la autonomía- refiere a la capacidad de tomar decisiones y hacer juicios sobre determinadas situaciones, con independencia de las interferencias externas que pretendan ejercer control en esferas íntimas y personales, impidiendo la libre elección; de modo que implica un reconocimiento de las capacidades e ideas de cada cual.

La facultad de autodeterminarse implica la protección normativa para dirigir la conducta en cualquier sentido deseado y se asumen los efectos de tal proceso, efectos que varían desde la leve -y no comunicante- alteración de la realidad, como es el caso de quien no ejerce autocuidado, hasta la efectiva lesión de un bien jurídico tutelado, con la consecuencial privación de la libertad como sanción. Jakobs (2005) considera que la autonomía existe en la medida en que el sujeto libre esté presente en la comunicación, lo cual implica que lo relevante no es su libertad sino su capacidad de comunicación.

La limitación de las libertades a consecuencia de la comisión de delitos de peligro abstracto lleva a pensar que estos dejan de ser una simple perturbación del orden público para pasar a ser fuentes de riesgo contra la seguridad, asumida esta como un derecho que debe ser salvaguardado por el Estado. Jakobs (1998) cree que la integridad se encuentra comprometida por la dificultad actual de distinguir con claridad la frontera entre el comportamiento permitido o deseado y el que desconoce la norma, límite que ha sido fijado para mantener el orden social. 
El funcionalismo limita las libertades, sejustifica desde la necesidad de protección de la confianza en la norma, para garantizar un beneficio mayor; esto resulta directamente violatorio del principio de autonomía. La protección del libre ejercicio de los derechos en igualdad de condiciones es una misión central del ordenamiento legal. Rousseau (2004) consideró que la estabilidad social requiere que todos cedan parte de su libertad -también en igual medida- para generar las condiciones de convivencia y disfrute de los derechos en un ámbito de comunidad, lo cual implica que la interpretación del principio de la autonomía en forma absolutista no solo contraviene su propio contenido, porque el ejercicio irrestricto de la libertad de un sujeto interviene en el goce de la libertad del otro.

La bioética busca respetar la autonomía y abstenerse de obstaculizarla, supone darle valor al individuo, reconociéndolo como igual, independientemente del rol que desempeñe en la sociedad, salvo que sus manifestaciones lesionen a los demás. No puede perderse de vista que la definición de lesión constituye un criterio completamente subjetivo, que implica en los procesos de definición la posibilidad de caer en arbitrariedades y abusos, riesgo que debe minimizarse acudiendo a los principios del Estado Social de Derecho, normas constitucionales y pautas de interpretación hermenéutica.

\section{Justicia}

La justicia actualmente se relaciona con la convivencia armónica de los ciudadanos; se podría definir de la forma tradicional de Ulpiano, como «dar a cada quien lo suyo», pero dicha definición ha sido deformada en el transcurso de la modernidad para dar lugar a diversas y múltiples concepciones del término, entre las cuales resalta aquella en la cual la justicia ha sido enlazada a una perspectiva distributiva de recursos para satisfacer las necesidades de todos por igual, en aplicación del ideal de equidad. Es posible afirmar que la perspectiva de justicia contemporánea conlleva implícita la pretensión de alcanzar el bien común, siempre y cuando se respete la dignidad.

La equidad y la igualdad llevan un significado diferente; la primera persigue valorar y solucionar las desigualdades desde la óptica de la justicia, mientras que la igualdad quiere evitarlas sin realizar mayor análisis de las mismas. El proceso de valoración realizado desde la equidad implica un inevitable componente subjetivo que impide absoluta neutralidad, componente que varía dependiendo del tipo de sociedad, el momento histórico y el grado de desarrollo material y de pensamiento de la misma. Estos factores enmarcan la toma de decisiones políticas y los procesos de construcción y materialización del derecho. Para Hernández (2008) la equidad es valorar las desigualdades desde la justicia social que predomine en una sociedad en determinado instante de su desarrollo. 
La bioética desconoce la discriminación negativa y propende por la discriminación positiva ante ciertas desigualdades; se tiene como instrumento de apreciación la proporcionalidad razonada en la determinación del contenido de deberes y cargas de los individuos. Amor (2005) estima que es injusto agravar en mayor medida el comportamiento de los débiles o imponer más cargas de las que se pueden soportar sin comprometer la propia dignidad de los asociados. La imposición de una pena por la comisión de un delito de peligro, que no lesiona efectivamente un bien jurídico, es una excesiva carga para su autor teniendo en cuenta que los límites de lo que constituye puesta en peligro son subjetivamente establecidos por el legislador y los jueces en los procesos de aplicación normativa, sin atender a criterios objetivos de análisis.

\section{CONCLUSIONES}

El derecho penal contemporáneo necesita una revisión de los principios que lo rigen a la luz del biocentrismo, con la finalidad de salvaguardar la dignidad humana, para que podamos sobrevivir como sociedad en principios y valores. Las escuelas sociológicas que han servido de fuente para el funcionalismo radical han terminado por crear una suerte de temor hacia el otro y la necesidad de deshumanizar. Se justifica castigar al enemigo y su vulneración de derechos porque el cometer un acto que va más allá de toda «humanidad» lo convierte en un animal ${ }^{5}$.

En los delitos contra la seguridad pública, el ciudadano ha venido siendo despersonalizado a tal punto que se discute la eventual pérdida de nacionalidad y la deportación de los inmigrantes delincuentes hacia el país de origen; se incrementa la desigualdad y el resentimiento de las personas frente a los que piensan diferente y se les llama terroristas; se polarizan los discursos y los individuos se ven identificados con un nacionalismo excluyente. Se hace necesario, entonces, investigar el contexto y la constitucionalidad de la Ley 1908 de 2018 a fin de establecer qué derechos fundamentales pueden verse afectados con su implementación.

El funcionalismo radical debe tener límites conforme a los establecidos por Ferrajoli y la bioética; sin desconocer en el proceso la existencia de un enemigo -figura presente en todo modelo penal histórico- sobre el cual ejercer todo el

5 Günter Jakobs, en una entrevista concedida al periódico La Nación de Argentina el 26 de julio de 2006, afirmó que el enemigo tiene menos derechos y debe ser tratado como un animal, la entrevista puede verse en https://www.lanacion.com.ar/826258-el-enemigo-tiene-menos-derechos-dice-gunther-jakobs. 
poder estatal, se debe mantener un contexto jurídico de respeto por la dignidad del llamado enemigo, así como una serie de modificaciones sistémicas que permitan hacer que el sistema sea más eficiente en la judicialización del infractor, y así otorgar un sentido real a la función de disuasión.

La bioética principialista y personalista otorga estándares de protección a la dignidad humana en el interior del sistema (sea cual sea), el cual requiere un replanteamiento generalizado con la finalidad de obtener la tan anhelada persuasión; es una reforma que requiere garantizar la certeza de la pena por la comisión de la conducta con la finalidad de disuadir al individuo; se construye así al individuo para lograr su resocialización, para evitar la repetición.

\section{REFERENCIAS}

Amor, J. (2005). Introducción a la bioética. Madrid: PPC, Editorial y Distribuidora, SA, 61.

Beauchamp T. y Childress J. (1979). Principles of Bioedical Ethics. Oxford University Press, New York, $2^{\circ}$ edition, pp. 148-149.

Burgos Velasco, J. M. (2013). ¿Qué es la bioética personalista? Un análisis de su especificidad y de sus fundamentos teóricos. Cuadernos de bioética, 24(1).

Casado, M. (1998). Los derechos humanos como marco para el bioderecho y la bioética. En Derecho biomédico y bioética (pp. 113-136). Comares.

Escobar J. y Aristizábal, C. (2011). Los principios en la bioética: fuentes, propuestas y prácticas múltiples. Revista Colombiana de Bioética, 6 (Especial), 76-108. recuperado el 19 de septiembre de 2016. http:/ / www.redalyc.org/html(1892/189222553006/

Escobar-Picasso, E. y Escobar-Cosme, A. L. (2010). Principales corrientes filosóficas en bioética. Boletín médico del Hospital Infantil de México, 67(3), 196-203.

Ferrajoli, L. (2009). Derecho y Razón: Teoría del garantismo penal. Madrid: Editorial Trotta.

Ferrari, V. (2013). Funciones del derecho. Madrid: Debate.

Ferro, M., Molina, L. y Rodríguez, W. (2009). La bioética y sus principios. Acta Odontológica Venezolana, 47(2), 481-487.

García, A. (2008). ¿Dogmática Penal Sistémica? Sobre la influencia de Luhmann en la teoría penal, en Funcionalismo, Teoría de Sistemas y Derecho Penal, trabajo elaborado en el marco del proyecto de investigación DGICYTPB97- 0859, Universidad de León. 
Goldschmidt, W. (1958). Introducción al derecho, estructura del mundo jurídico. Buenos Aires: Aguilar.

Gracia, D. (1991). Introducción a la bioética. Siete ensayos. Bogotá: Editorial El Búho.

Hernández, M. (2008). El concepto de equidad y el debate sobre lo justo en salud. Revista de Salud Pública, 10(1), 72-82. Recuperado el 19 de septiembre de 2016. http://www.cielo.org/pdf/rsap/v10s1/v10s1a07.pdf.

Jakobs, G. (1998). Sociedad, Norma, Persona (Primera ed.). (M. Cancio Meliá, \& B. Feijoo Sánchez, Trads.) Bogotá: Universidad Externado de Colombia. Recuperado el 19 de septiembre de 2016. http:/ / www.derechopenalenlared.com/libros/jak Derecho-Penal-Funcional.pdf

Jakobs, Günther. (2005). La pena estatal: significado y finalidad., el fundamento del Sistema Jurídico Penal, traducida por Manuel Cancio Melia y Bernardo Feijoo Sánchez, Lima: Ara, p. 62.

Juárez, Fernando. (2004). El concepto de salud: Una explicación sobre su unicidad, multiplicidad y los modelos de salud. International Journal of Psychological Research. Bogotá: Universidad del Rosario.

Kant, I. (1983). Fundamentación de la metafísica de las costumbres. Cap. II. Tratado de M. García Morente. Madrid: Espasa.

La Nación, A. A. (2006). El enemigo tiene menos derechos. Cultura. Diario La Nación. Buenos Aires. p. 17 en https:/ / www.lanacion.com.ar/826258-el-enemigo-tienemenos-derechos-dice-gunther-jakobs

Luhmann, N. (1983). Sistema jurídico y dogmática jurídica, trad. de Ignacio de Otto Pardo. Madrid: CEC.

Malinowski, B. (1981). Una teoría científica de la cultura. Barcelona: Edhasa.

Merton, R. K. (2002). Teoría y estructuras sociales. México D. F.: Fondo de Cultura Económica.

Morris, D \& Aleu, J.F. (1993).El mono desnudo. RBA.

Montero, E. (2008). El funcionalismo penal, una introducción a la teoría de Günther Jakobs. Trujillo, Perú: Ed. Trujillo.

Neuman, E. (1983). Victimología y control social: Las víctimas del sistema penal. Córdoba: Universidad. 
Parsons, T. (1999). El sistema social. Madrid: Alianza.

Polaino, M. (2004). Derecho Penal. Modernas bases dogmáticas. Lima: Grijley.

Potter, V. R. (1971). Bioethics bridge to the future. New York: Prentis Hall.

Rousseau, J. (2004). El contrato social. Barcelona: Editorial Istmo.

Samperio, C. y Barrachina, M. (2007). Bioética y biojurídica. Medicina y ética: Revista internacional de bioética, deontología y ética médica, 18(1), 53-70. Recuperado el 19 de septiembre de 2016. http:/ / philpapers.org/rec/SAMBYB

Torres, H. (2009). El terrorismo en el código penal colombiano. Revista Logos ciencia y tecnología, Policía Nacional, 1, 137-154.

Velásquez V. (2010). Manual de Derecho Penal. Bogotá: Ediciones Jurídicas Andrés Morales.

(2005). El funcionalismo jakobsiano: una perspectiva latinoamericana. Revista de derecho y criminología. Universidad de Antioquia, 15, 197-219.

Wright, C. R. (1959). Mass communication: A sociological perspective (Nro. P. 90 W7).

\section{Jurisprudencia}

Colombia. Corte Constitucional Sala Plena. Sentencia T- 452 del 15 de junio de 2010. M. P. Humberto Sierra Porto. [En línea]. [Fecha de consulta: 28 de febrero de 2018]. Disponible en http://www.corteconstitucional.gov.co/relatoria/2010/t-45210.htm

\section{Leyes}

Colombia. Congreso de la República. Ley 599 (24 de julio de 2000). Por la cual se expide el Código Penal. Diario Oficial. Bogotá, D. C., 2000. N.o 44097. 